\title{
Türkiye'nin İş Kazaları Açısından Durumu: ILOSTAT ve SGK Verileri Karşılaştırması
}

\author{
Turkey's Situation Regarding Work Accidents: Comparison of ILOSTAT and SSI \\ Data
}

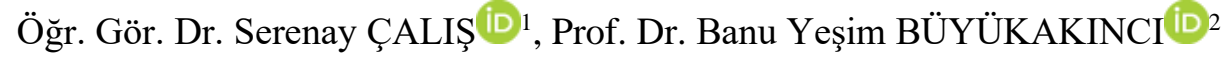

\begin{abstract}
$\ddot{O} z$
İş kazaları, ülkelerin dikkate aldığı ve önlemeye çalıştığı maliyet unsuru ve insanın zarar görmesinden dolayı sosyal tarafı olan kazalardır. İş kazaları sadece çalışanı değil, ailesi, iş yeri ve işvereni ve ülkeyi de ciddi şekilde etkilemektedir. Bu nedenle hem ulusal hem de uluslararası düzeyde iş sağlığ uygulamalarının yaygınlaştırılması için çalışmalar devam etmektedir. Bu çalışmalar içinde iş kazalarının engellenebilmesi için yapılacak faaliyetler yer almaktadır. İş kazalarını önlemek için sağlık ve teknik önlemler alınmakta ancak bu önlemler bazen yeterli olmamaktadır. Türkiye'de yaşanan iş kazaları da göstermektedir ki alınan önlemler yetersizdir. Aslında iş kazaları istatistikleri incelendiğinde sorunun temelinin nereden kaynaklandığı ve özellikle hangi alanlarda önlemlerin yetersiz olduğu açıkça görülebilmekte ancak bu durum dikkate alınmadığından iş kazaları artarak devam etmektedir. Ayrıca istatistiklerle ilgili önemli olan konu ulusal ve uluslararası verilerin tutarlılığıdır. Bu çalışma ile amaçlanan Türkiye'nin iş kazalarındaki durumunu, 2013-2016 yılları arasındaki ILOSTAT ve SGK verilerini karşılaştırarak ortaya çıkarmaktır. Burada istenilen verilerin tutarlılığını ortaya çıkarmaktır. Veriler, SGK ve ILOSTAT'ın resmî web adreslerinden elde edilerek karşılaştırmaya olanak verecek şekilde tablolaştırılmıştır. Veriler değerlendirildiğinde SGK ile ILOSTAT verilerinin neredeyse aynı olduğu görülmüştür. Sadece 2016 yılına ait ölümlü olmayan iş kazası verilerinde büyük bir farklılık söz konusudur. Bu da gösteriyor ki, Türkiye'de yayımlanan veriler önemli ölçüde uluslararası verilerle örtüşmektedir.
\end{abstract}

Anahtar Kelimeler: Türkiye, iş kazası istatistikleri, ILOSTAT, sosyal güvenlik kurumu

Makale Türü: Araştırma

\begin{abstract}
Work accidents are accidents that countries regard seriously and try to prevent for both having a social aspect because of the cost element as well as the harming of the people. Occupational accidents not only cause serious problems for employees, but also for family, workplace, employer and country. Therefore, efforts are continuing to promote occupational health and safety practices at both national and international levels. Health and technical measures are taken to prevent occupational accidents, but sometimes these measures are not sufficient. Work accidents that occur in Turkey show that the measures taken are inadequate. Importantly, the national and international data are consistent with each other. This study aims to uncover Turkey's situation regarding work accidents by comparing ILOSTAT and SSI data between the years of 2013-2016. The purpose of using these data is to reveal the consistency in the data. Data were obtained from the official web addresses of SSI and ILOSTAT and tabulated for comparison. When the data were evaluated, it was seen that SSI and ILOSTAT data were almost identical. Only in the 2016 non-fatal occupational accident data, there is a large discrepancy. This shows that the data published in Turkey are consistent with international data significantly.
\end{abstract}

\footnotetext{
${ }^{1}$ Niğde Ömer Halisdemir Üniversitesi, Niğgde Teknik Bilimler Meslek Yüksekokulu, calis.serenay@gmail.com.

${ }^{2}$ İstanbul Aydin Üniversitesi, Mühendislik Fakültesi, yesimbuyukakinci@aydin.edu.tr.
} 
Keywords: Turkey, work accidents statistical, ILOSTAT, social security institution

Paper Type: Research

\section{Giriș}

"İ̧s Sağlı̆̆ ve Güvenliği, genel olarak, çevre topluluklar ve genel çevre üzerindeki olası etkileri hesaba katarak, iş yerinde veya iş yerinden kaynaklanan tehlikelerin tahmin edilmesi, tanınmas1, değerlendirilmesi ve kontrolü olarak tanımlanmaktadır" (ILO, 2016, s. 18). Tanımda belirtildiği gibi iş sağlığı ve güvenliğinde amaç iş kazası olmadan önce potansiyellerin belirlenmesi ve belirlenen potansiyellerin ortadan kaldırılarak zarar verici etkisinin yok edilmesidir. İş sağlığı ve güvenliğinin sağlanması için alınan önlemler, iş ilişkisi türü ve çalıştığ şirketin büyüklüğü ne olursa olsun ulaşabileceği en yüksek sayıda çalışana ulaşmalıdır (European Commission, 2017, s. 3). Bir çalışanın bile göz ardı edilmesi, alınan tüm önlemlerin ortadan kaldırılması anlamına gelmektedir. İş sağlığı ve güvenliği faaliyetlerine ancak her çalışanın dahil edilmesiyle aktif bir döngü sağlanabilir, bu şekilde sistem sürekli canlı tutulabilir. Yani çalışanların korunması küresel toplumların yanı sıra yerel yönetimler ve işletmeler tarafından da önemsenmesi gereken bir konudur (Moyce and Schenker, 2018, s. 360).

"İş sağllğı ve güvenliği, çalışanların işin olumsuz yönlerine, iş kazalarına ve meslek hastalıklarına karşı sosyal korunmasının önemli bir bileşenidir. İş memnuniyetini arttırır, iş gücü piyasasının işleyişini ve insan sermayesinin kalitesini güçlendirir. İş sağllğ ve güvenliğinin eksik uygulanması ise yaralanmalar, ölümler ve meslek hastalıkları, gelir bağlanması, hastane masrafları, işçilerin yeniden eğitilmesi, değiştirilmesi ve verimlilik kaybı ile de ülke ekonomisine büyük yük getirmektedir" (ILO, 2016, s. 18). Bu nedenle ülkeler, teknik ve sosyal önlemlerin yanında durumlarını görebilmek için iş kazası verilerini de sistematik olarak kaydetmektedir. Bu veriler hem ulusal düzeyde hem de uluslararası düzeyde çalışma hayatının verilerini kaydeden kuruluşlar tarafindan gerçekleştirilmektedir. Türkiye'de resmi veriler Sosyal Güvenli Kurumu (SGK) tarafından tutulmaktadır. Türkiye ile ilgili ulaşılabilen diğer veriler ise ILOSTAT tarafından sağlanmıştır.

SGK, Türkiye'de T.C. Aile, Çalışma ve Sosyal Hizmetler Bakanlığı bünyesinde faaliyet gösteren, çalışma hayatında yer alan kişilerin sigortalılıkları, gelirlerinin bağlanması ve daha diğer birçok faaliyetin yürütüldügü kurumdur. Kısacası Sosyal Güvenlik Kurumu, "sosyal yardıma ihtiyacı olan herkesin ihtiyacını karşılamakla yükümlüdür” (Doğan, 2013, s. 85). Ayrıca çalışma hayatı istatistikleri SGK' de toplanır ve aylık, yıllık olarak yayımlanır. ILOSTAT ise, Uluslararası Çalışma Örgütü'nün faaliyetleri kapsamında ülkelerin çalışma hayatı ile ilgili verilerine ulaşmaya çalışan istatistik birimidir. ILOSTAT, kullanıcılara işgücü ile ilgili geniş bir alanda kapsamlı uluslararası veriler sağlar (ILOSTAT, 2019).

Yapılan bu çalışmada, ulusal ve uluslararası veriler dikkate alınarak Türkiye'nin iş kazası verileri, yıllar itibariyle karşılaştırılmış ve farklılıkların olup olmadığı ortaya çıkarılmıştır. Elde edilen sonuca göre uluslararası veriler ile ulusal veriler arasında anlamlı farklılığın sadece ölümlü olmayan iş kazaları 2016 yılı verilerinde olduğu, diğer yıllara ait verilerin ise tutarlı olduğu görülmüş̧ür.

\section{1. İş Sağlığı ve Güvenliği}

İş sağlığı ve güvenliği kavramı doğrudan çalışma yaşamı için kullanılan bir kavramdır. $\mathrm{O}$ halde çalışma yaşamı insanlar için önemli mi sorusunun cevabını bilmek de gerekmektedir. Her yerde iş sağllğı ve güvenliği önlemlerinin uygulanması gerektiği vurgulanmakta ancak neden insan hayatı için bunun önemli olduğu çok fazla detaylandırılmamaktadır. "Çalışma hayatı, iş yerinin benimsediği politikalar, yaptıkları hizmetler, çalışanlarına karşı tutumları, çalışanların sağlık ve güvenlik açısından iyi olmaları, süreçlerin yönetimindeki standartlar ve 
etkinlik, aile ile kişisel yaşam arasındaki dengedir (Telman ve diğerleri, 2015, s. 7).” Bu yönüyle çalışma yaşamında yer alan bireyin sosyal hayatından tamamen koparak çalışmayı sürdürmediği, çevresinden etkilendiği, iş yerindeki mutluluğunun önemli olduğunu söyleyebiliriz. Çalışma hayatında bu kadar unsuru bir arada dengede tutmaya çalışıyorsak neden emeğimizi arz ediyoruz?

İnsanların çalışma ihtiyacı duyması ile ilgili nedenler şu şekilde belirtilmiştir (Telman ve diğerleri, 2015, s. 9-10):

1. Aile geçindirmek,

2. Para kazanmak,

3. Maddi gelir elde etmek,

4. Kira, geçim maliyeti karşılamak,

5. Tanrı çalışmayanı sevmediğinde,

6. Toplumda yer edinmek,

7. Aile reisi olmak,

8. Bir şeyler yapabildiğini ispat vb.

Yukarıdaki maddeler insanların neden çalışması gerektiği ile alakalı ufak bir bilgi vermektedir. Türkiye'de insanların toplumsal rollerinden dolayı özellikle erkek bireylerin çalışması beklenmekte, çünkü onlara aile reisliği (Can, 2013, s. 233) sorumluluğu yüklenmektedir. Yani insanlar para kazanabilmek ve hayatta kalabilmek için çalışmak zorundadır. Bunun tam tersini düşünecek olursak, çalışmayan ve para kazanamayan bireylerin sağlıklı olarak toplumda ayakta kalmaları mümkün değildir. Bu nedenle çalışmak zorunda olan insanların bu zorunluluktan dolayı zarar görmemeleri devletlerin önemsemeleri gereken bir husustur. Çünkü devleti ayakta tutan çalışan ve üreten insan potansiyelidir.

İnsanların çalışma hayatında yer almalarından dolayı zarar görmemeleri için iş sağlığı ve güvenliği çalışmaları uygulanmakta, bu çalışmalar çalışanların hayatlarını koruma altına alan faaliyetleri kapsamaktadır. Bu yönüyle Anayasa'da ifade edilen ve hiç kimsenin dokunamayacağı hak olan yaşama hakkını da (KAYSİS, 2020c) sağlamaya çalışan bir alandır. Aslında yaşama hakkı denildiğinde sadece kişilerin ölmemesi anlaşılmamalıdır, bunun yanı sıra kişilerin sağlıklarını kaybetmemeleri, vücut bütünlüklerinde herhangi bir eksikliğin oluşmaması da kastedilmektedir (Akpınar, 2018, s. 3).

İnsan hayatının korunmasının söz konusu olduğu bu alan pek çok farklı şekilde tanımlanmakta ancak aslında bütün tanımlar ortak bir noktada buluşmaktadır. Bu ortak nokta ise çalışanların güvenli ve sağlıklı ortamda çalışması ve yapılan işten dolayı herhangi bir sağlık ve güvenlik hasarına uğramamasıdır (Sümer, 2017, s. 5; Yiğit, 2011, s. 2; Akar ve Şık, 2015, s. 1112). İş sağlıği ve güvenliği Türkiye'de uzun yıllardır mevzuatta yerini almakta ancak 2012 yılında 6331 sayılı İş Sağlığı ve Güvenliği Kanunu çıkarılana kadar özel bir alan olarak düzenlenmemekteydi. Kanun ile ulusal faaliyetler ve bu faaliyetlerle her alanda koruma tedbirlerinin uygulanması çalışmaları desteklenmeye başlamıştır.

\section{Türkiye'nin İş Kazaları Açısından Durumu}

İş kazaları, yetersiz istihdam ve çalışma koşullarının gözle görülür yan etkilerinden biridir. Bu etkiler her sektörde eşit değildir. Tarım, sanayi, hizmet sektörü gibi farklı sektörlerde farklı sonuçlar ortaya çıkmakta, ancak bu sonuçlar gelişmiş ülkelerde alınan önlemler sayesinde azalarak devam etmektedir. Buna karşın gelişmekte olan ülkelerde durum tam tersini göstermektedir. Bunun nedeni sanayileşmenin daha hızlı olması ve kentsel yaşam tarzının daha çok benimsenmesi nedeniyle inşaat sektöründeki artış ve tarımdaki geleneksel üretim yöntemlerinin hala kullanılıyor olmasıdır (Benach vd., 2007, s. 78).

İş yerlerinde meydana gelen kazalar ve bunların sonucundaki yaralanmaklar ya da hastalıklar çalışma çağındaki nüfus için önemli bir yük getirmektedir. Bu yük maliyet (Fontaneda vd., 2019, s. 23; Jabbari ve Ghorbani, 2016, s. 101) unsurunu ifade etmekle birlikte 
aileleri de zor duruma düşürmekte ve var olan sosyal ve ekonomik durumu da kötüleştirmeye neden olabilmektedir (Lay vd., 2007, s. 85). Bu nedenle dünya genelinde bile önemli bir halk sorunu olarak kabul edilmektedir (Hansen, 2019, s. 283). Önlemlerin alınabilmesi ve kazaların önlenebilmesi için de iş kazası analizleri yapılmak zorundadır (Jeong ve Shin, 2016, s. 316).

Türkiye'de iş sağlığ 1 ve güvenliği ile ilgili doğrudan düzenlemelerin yer aldığ kanunlar 6331 Sayılı İş Sağlığı ve Güvenliği Kanunu ile 5510 Sayılı Sosyal Sigortalar ve Genel Salık Sigortası Kanunu'dur. 6331 sayılı kanun daha dar bir iş kazası tanımı içermekte iken 5510 sayılı kanun daha ayrıntılı düzenlemeleri barındırmaktadır. 6331 sayılı kanuna göre "iş kazası (KAYSIS, 2020b), işyerinde veya işin yürütümü nedeniyle meydana gelen, ölüme sebebiyet veren veya vücut bütünlüğünü ruhen ya da bedenen engelli hâle getiren olaydır." Ayrıca kanun içerisinde bildirim yükümlülüğü (KAYSİS, 2020b) ile ilgili de düzenleme bulunmaktadır.

Türkiye'de iş kazası ile ilgili ayrıntılı ve hukuken de iş kazası tanımında dikkate alınan düzenleme 5510 sayılı Sosyal Sigortalar ve Genel Salık Sigortası Kanunu'dur. Kanunun 13. maddesine göre (KAYSİS, 2020a): "İş kazas1;

a) Sigortalının işyerinde bulunduğu sırada,

b) İşveren tarafindan yürütülmekte olan iş nedeniyle sigortalı kendi adına ve hesabına bağımsız çalışıyorsa yürütmekte olduğu iş nedeniyle,

c) Bir işverene bağlı olarak çalışan sigortalının, görevli olarak işyeri dışında başka bir yere gönderilmesi nedeniyle asıl işini yapmaksızın geçen zamanlarda,

d) Bu Kanunun 4üncü maddesinin birinci fikrasının (a) bendi kapsamındaki emziren kadın sigortalının, iş mevzuatı gereğince çocuğuna süt vermek için ayrılan zamanlarda,

e) Sigortalıların, işverence sağlanan bir taşıtla işin yapıldığı yere gidiş gelişi sırasında, meydana gelen ve sigortalıyı hemen veya sonradan bedenen ya da ruhen engelli hâle getiren olaydır."

Eğer herhangi bir kaza yukarıdaki durumlardan birini taşıyorsa iş kazası olarak kabul edilmektedir. Yine yukarıda adı geçen kanunun 13. maddesi iş kazası yaşayan iş yerlerinin bu durumu SGK'ye bildirme zorunluluğu da düzenlenmiştir. Maddeye göre (KAYSİS, 2020a);

“a) (a) bendi ile 5 inci madde kapsamında bulunan sigortalılar bakımından bunları çalıştıran işveren tarafından, o yer yetkili kolluk kuvvetlerine derhal ve Kuruma da en geç kazadan sonraki üç işgünü içinde,

b) (b) bendi kapsamında bulunan sigortalı bakımından kendisi tarafindan, bir ay1 geçmemek şartıyla rahatsızlığının bildirim yapmaya engel olmadığı günden sonra üç işgünü içinde,

c) (c) bendi kapsamında bulunan sigortalılar bakımından, bunları çalıştıran işveren tarafından, o yer yetkili kolluk kuvvetlerine veya kendi mevzuatlarına göre yetkili mercilere derhal ve Kuruma da en geç kazadan sonraki üç işgünü içinde iş kazası ve meslek hastalığ bildirgesinin doğrudan ya da taahhütlü posta ile Kuruma bildirilmesi zorunludur. Bu fikranın (a) ve (c) bentlerinde belirtilen süre, iş kazasının işverenin kontrolü dışındaki yerlerde meydana gelmesi halinde, iş kazasının öğrenildiği tarihten itibaren başlar."

İş kazalarının özelliklerinin tanımlanabilmesi ve iş kazası yapısının ortaya koyulabilmesi için istatistiklerin bilinmesi gerekmektedir (Pietila vd., 2018, s. 270). 2012 yılında İş Sağlığı ve Güvenliği Kanunu'nun yürürlüğe girmesinden sonra iş kazası kayıtlarının tutulması daha bilimsel ve az hataya yer verecek şekilde olmaya başlamıştır. Bildirim zorunluluğu sayesinde hem ülkeler kendi iç yapılarını rahatlıkla görebilmekte hem de uluslararası düzeyde her ülke kendini diğeri ile karşılaştırarak diğer uygulamaları örnek alma imkânı olmaktadır.

Türkiye'de de ulusal düzeyde tutulan veriler uluslararası platform ile kendimizi karşılaştırma imkânı sunmaktadır. Bu nedenle verilerin düzenli tutulması büyük önem 
taşımaktadır. Türkiye'deki veriler incelendiğinde 2013-2017 yılları arasında meydana gelen iş kazaları ve ölümlü iş kazası sayıları grafiklerde gösterilmiştir.

Grafik 1, Türkiye'de 2013 yılından itibaren iş kazası sayısının artarak devam ettiğini göstermektedir. Bununla beraber ölümlü iş kazası sayısı değişiklik göstermekle beraber bir önceki yıla göre artışına devam etmiştir. Bu durum iş sağlı̆̆ 1 ve güvenliği faaliyetlerinin ne seviyede devam ettiğini de vurgulamaktadır.

Grafik 1. 2013-2017 yılları arasında Türkiye'de meydana gelen toplam iş kazası ve toplam ölümlü iş kazası sayısı

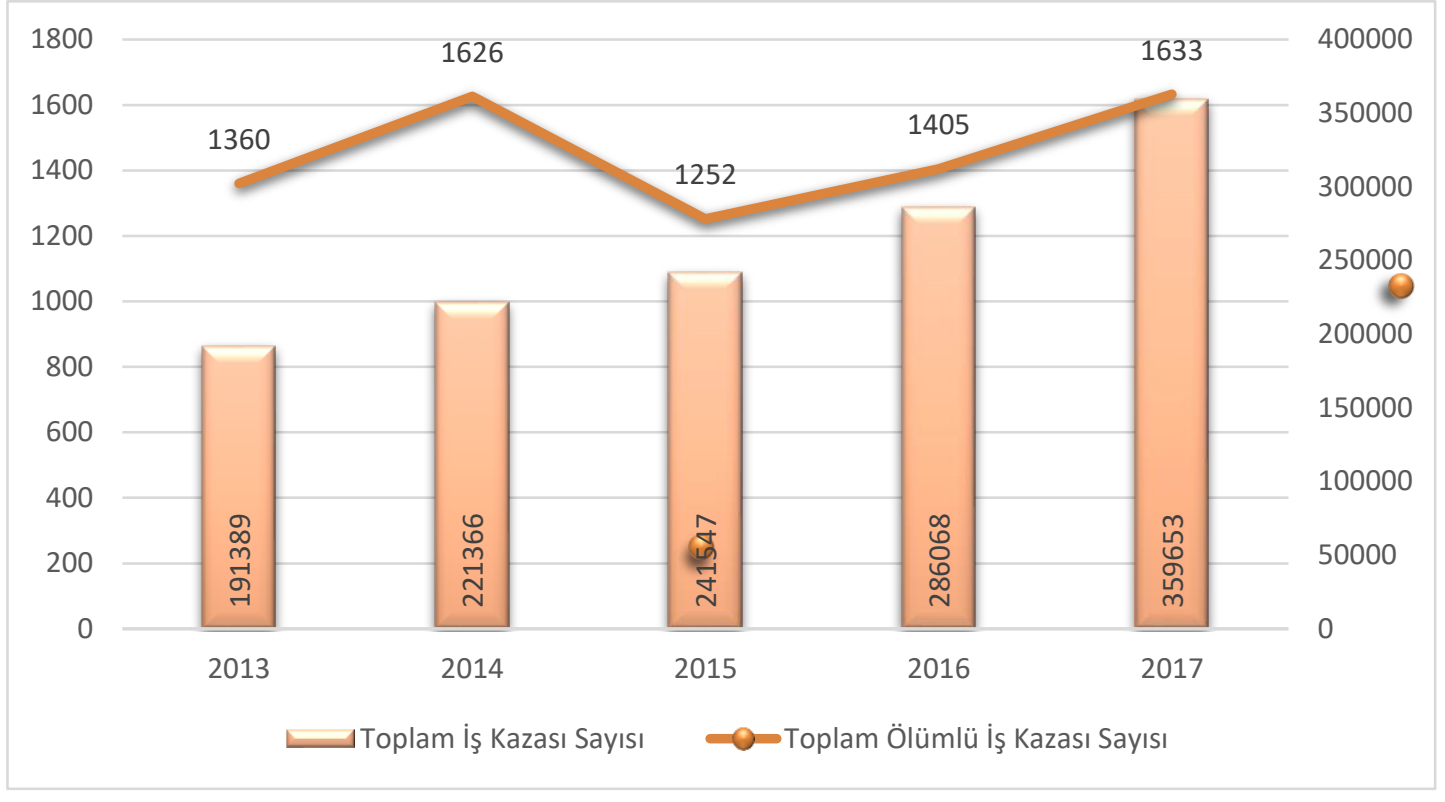

Kaynak: SGK, 2019

Grafik 2, 2013-2017 yılları arasında Türkiye'de meydana gelen ölümlü iş kazalarının cinsiyet dağılımını göstermektedir. Bütün yıllarda görülüyor ki erkek çalışanların sayıları kadın çalışanlardan fazladır. Bunun en temel nedeni çok tehlikeli ve tehlikeli işlerde kadınların değil erkeklerin istihdam edilmesi olduğu söylenebilir.

Grafik 2. 2013-2017 yılları arasında Türkiye'de meydana gelen ölümlü iş kazalarının cinsiyete göre dağılımı

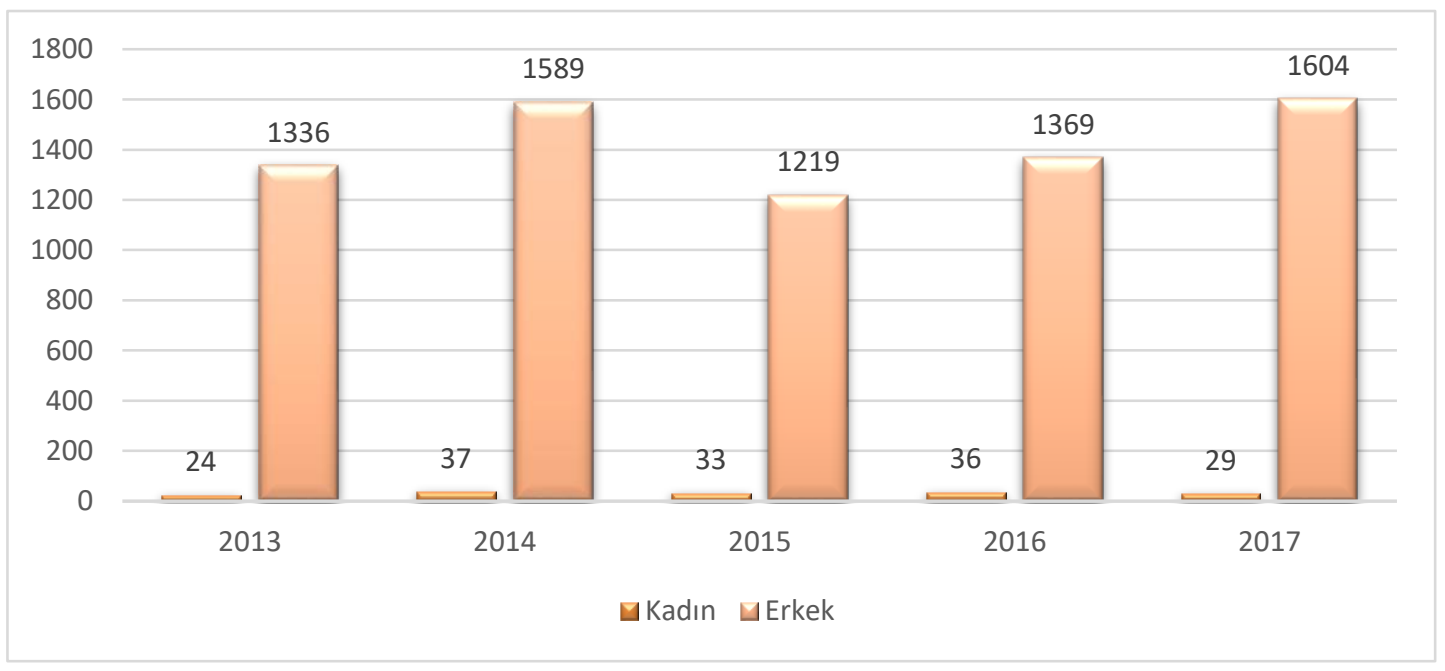

Kaynak: SGK, 2019. 
Veriler yıllar itibariyle, çalışan sayısına ve iş kazası sayısına göre analiz edildiğinde, Grafik 3'teki sonuçlar elde edilmiştir. Bu verilere göre, toplam çalışan sayısı ve iş kazası sayısı son 5 yılda sürekli artmıştır. Artan veriler arasındaki artış oranları incelendiğinde 2013-2014 yılları arasında çalışan sayısı \%6,3 (831498)'lük artış gösterirken, iş kazası sayısı (29977) $\% 15,66$ artmıştır.

Grafik 3. Toplam iş kazası ve çalışan sayısı karşılaştırması ve yüzdelik değişimleri

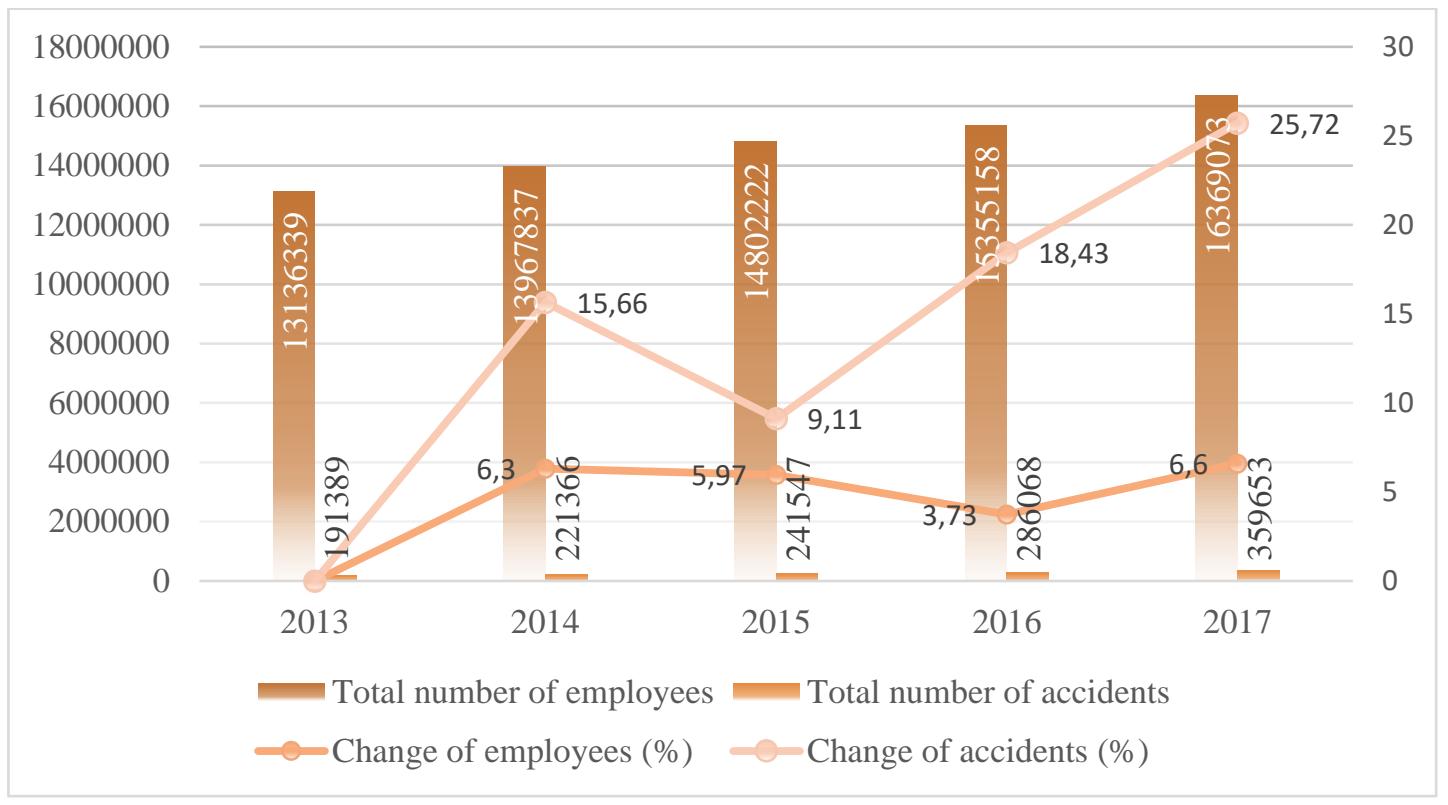

Kaynak: SGK, 2019

2014-2015 yılları arasında çalışan sayısı (834385) \%5,97'lik artış oranına sahipken, iş kazas1 sayıs1 $(20,181) \% 9,11$ oranında artmıştır. 2015-2016 yılları arasındaki oranlar incelendiğinde çalışan sayısı (552936) 3,73 artış göstermiş, iş kazası sayısı (44521) \%18,43 oranında artmıştır. Son olarak, 2016-2017 yılları arasında çalışan sayısı \%6,6 (1013915), iş kazası sayısı \%25,72 artmıştır (73585). Önemli olan husus elde edilen verilerin ne kadar doğru ve güvenilir olduğudur. Bu nedenle yapılan çalışmada ILOSTAT ve SGK verilerinin tutarlı olması önemlidir.

\section{Araştırmanın Amacı ve Önemi}

Bu çalışma ile amaçlanan Türkiye'de resmi kuruma bildirilen iş kazası istatistikleri ile uluslararası platformda faaliyetlerini sürdüren Uluslararası Çalışma Örgütü'nün yayımladığ verilerin birbirini destekleyip desteklemediğini ortaya çıkarmaktır. Çalışma sonucunda elde edilen veriler ile Türkiye'de yayımlanan verilere ne kadar güvenebileceğimiz belirlenirken ayrıca Türkiye'nin iç yapısına ait iş kazası durumunun güncel halinin doğru olup olmadığı da belirlenebilecektir.

\section{Yöntem}

Çalışmada tanımlayıcı araştırma yöntemi tercih edilmiştir. Bu yöntem, bir problemle ilgili durumları, değişkenleri ve değişkenler arasındaki ilişkileri tanımlamaya yönelik olarak kullanılan bir araştırma yöntemidir (Yıldırım ve Asal, 2012, s.105). Çalışma içinde yer alan SGK verileri, kurumun resmi internet sayfasında her yıl yayımlanan istatistik yıllıkları yoluyla elde edilmiştir. Diğer verileri oluşturan ILOSTAT verilerine de benzer şekilde ILOSTAT'a ait resmi internet sitesinden ulaşılmıştır. SGK, Excel yazılımı üzerinden verileri sağlarken, ILOSTAT doğrudan kendi internet sayfası üzerinden verileri yayımlamıştır. Verilerin yazar tarafından tablolara aktarılması yolu ile karşılaştırma yapabilme olanağının kolaylaştırılması sağlanmıştır. Her iki kurumdan alınan verilerin yıllara göre ölümlü ve ölümlü olmayan iş 
kazaları sayıları ile ekonomik faaliyet sınıfına göre ölümlü iş kazaları sayıları tablolar halinde sunulmuştur.

İlk olarak ölümlü olmayan ve ölümlü iş kazaları olarak 2 farklı durum incelenmiş ve bu başl1klar da yıllara göre ayrılmıştır. Yıllar 2013-2016 olarak belirlenmiştir. 2013 yılının sınır alınmasının nedeni Türkiye'de ilk defa 2012 yılında iş sağlığı ve güvenliği ile ilgili kanunun yürürlüğe girmesidir. 2016 yılının sınır alınmasının sebebi ise ILOSTAT' ta Türkiye ile ilgili verilerin en son bu yıl için yayımlanmış olmasıdır.

İkinci olarak ise kazalar ekonomik faaliyet sınıflarına göre sınıflandırılarak değerlendirilmiştir. Buradaki kısıtlar da aynı nedenle çalışmanın belli tarih aralığını kapsamasına neden olmaktadır.

Tablolar içinde belirtilen yüzde farklar ise formüle edilerek bulunmuştur. Formül Excel programına girilerek hata payını ortadan kaldıracak şekilde hesaplanmıştır. Formül aşağıda belirtildiği gibidir:

$$
Y \ddot{u} z d e \text { farkl }=\frac{S G K-I L O S T A T}{I L O S T A T} \times 100
$$

\section{Bulgular ve Tartışma}

Yapılan araştırmalar sonucunda Tablo 1 ve Tablo 2'de gösterilen verilere ulaşılmıştır. İlk olarak ölümlü olmayan kazalar incelenmiş (Tablo 1) ve kazaların yıllar itibariyle hem SGK hem de ILOSTAT verilerinde artarak devam ettiği görülmüştür.

Tablo 1. Ölümlü olmayan iş kazalarının SGK ve ILOSTAT verileri ile karşılaştırılması

\begin{tabular}{|c|c|c|c|c|c|}
\hline \multirow[t]{2}{*}{ Yillar } & \multicolumn{2}{|c|}{ SGK } & \multicolumn{2}{|c|}{ ILOSTAT } & \multirow[t]{2}{*}{ Yüzde Fark1 } \\
\hline & Erkek & Kadın & Erkek & Kadın & \\
\hline 2013 & 20.745 & 170.644 & 20.728 & 170.656 & \\
\hline Toplam* & \multicolumn{2}{|c|}{191.389} & \multicolumn{2}{|c|}{191.384} & $\sim 0,00003$ \\
\hline 2014 & 28.174 & 193.192 & 28.144 & 193.227 & \\
\hline Toplam* & & & & & $\sim 0,00003$ \\
\hline 2015 & 34.625 & 206.922 & 34.613 & 206.922 & \\
\hline Toplam* & \multicolumn{2}{|c|}{241.547} & \multicolumn{2}{|c|}{241.535} & $\sim 0,00005$ \\
\hline 2016 & 44.953 & 241.115 & 44.896 & 241.021 & \\
\hline Toplam* & \multicolumn{2}{|c|}{286.068} & \multicolumn{2}{|c|}{287.917} & $\sim 0,0064$ \\
\hline
\end{tabular}

* ILOSTAT verilerinde göçmenlerin geçirdiği ölümlü olmayan iş kazası sayıları da bulunmaktadır. ILOSTAT, göçmen sayılarını toplam ölümlü iş kazası sayısına dahil etmediğinden çalışmada da göçmen iş kazası sayıları kullanılmamıştır.

Kaynak: SGK, 2019; ILOSTAT, 2019

SGK ve ILOSTAT verileri arasındaki fark, 2013 ve 2014 yıllarında toplam iş kazası sayısında 5 kişilik bir farkın olduğu görülmektedir. Bu farklılığın hangi verilerden kaynaklandığı ise yüzde farkı sütununda ifade edilmiştir.

SGK'ye göre belirlenen fark yüzdelerine göre 2013 yılındaki fark SGK verilerinin daha yüksek olmasından, 2014 yılında ise ILOSTAT verilerinin daha yüksek olmasından kaynaklanmaktadır. 2015 yılında ise farkın 12 kişi olduğu, yüzde farkının ise $\sim 0,00005$ olduğu bulunmuştur. $\mathrm{Bu}$ farklılığın kaynağı ise SGK istatistiklerinin ILOSTAT verilerine göre daha fazla olmasıdır. Son olarak 2016 yılında ise fark en yüksek seviye ile 1849 kişidir. Fark yüzdesinin -0,0064 olarak belirlenmesi göstermektedir ki, SGK verilerinde daha az kaza kaydedilmiş olmakla beraber ILOSTAT verilerinde daha fazla kaza kaydı bulunmaktadır. Ölümlü olmayan iş kazaları içerisinde en fazla farkın bulunduğu yıl 2016 olarak belirlenmiştir. Grafik 4'te dağılım gösterilmiştir. 
Grafik 4. Ölümlü olmayan iş kazası verileri karşılaş̧ırması

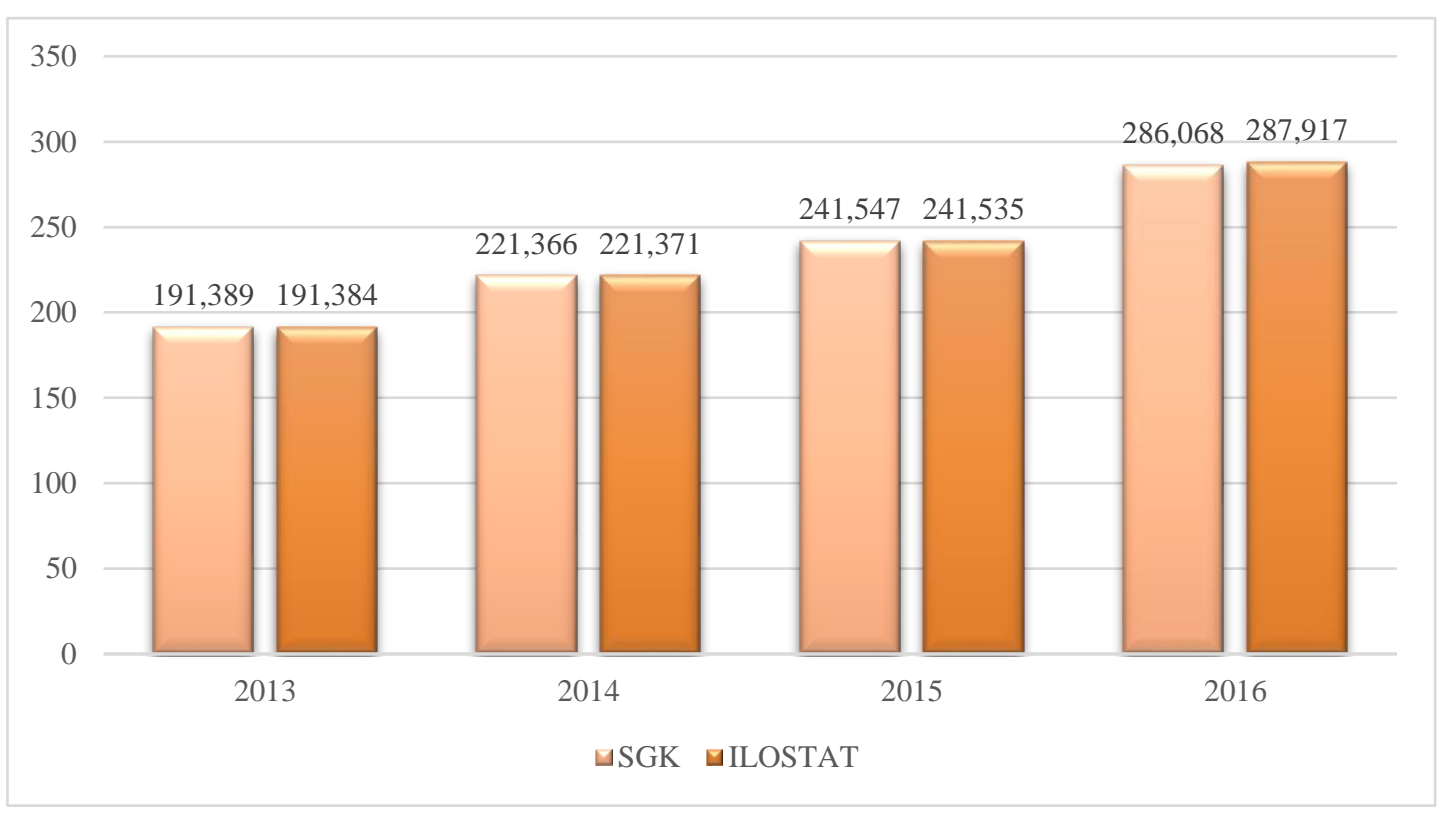

Kaynak: SGK, 2019; ILOSTAT, 2019.

Tablo 2'de ise ölümlü iş kazaları verileri gösterilmiştir. Veriler incelendiğinde yıllar itibariyle artış ve azalış olduğu ancak bir önceki yıla göre ölümlü iş kazalarının arttığ görülmüştür.

Tablo 2. Ölümlü iş kazalarının SGK ve ILOSTAT verileri ile karşılaştırılması

\begin{tabular}{|c|c|c|c|c|c|}
\hline \multirow[t]{2}{*}{ Y1llar } & \multicolumn{2}{|c|}{ SGK } & \multicolumn{2}{|c|}{ ILOSTAT } & \multirow[t]{2}{*}{ Yüzde Fark1 } \\
\hline & Erkek & Kadin & Erkek & Kadın & \\
\hline 2013 & 1336 & 24 & 1337 & 23 & \\
\hline Toplam* & \multicolumn{2}{|c|}{1360} & \multicolumn{2}{|r|}{1360} & 0 \\
\hline 2014 & 1589 & 37 & 1592 & 36 & \\
\hline Toplam* & \multicolumn{2}{|c|}{1626} & \multicolumn{2}{|r|}{1628} & $\sim-0,0013$ \\
\hline 2015 & 1219 & 33 & 1221 & 33 & \\
\hline Toplam* & \multicolumn{2}{|c|}{1252} & \multicolumn{2}{|r|}{1254} & $\sim-0,0016$ \\
\hline 2016 & 1369 & 36 & 365 & 36 & \\
\hline Toplam* & \multicolumn{2}{|c|}{1405} & \multicolumn{2}{|r|}{1401} & $\sim 0,0029$ \\
\hline
\end{tabular}

* ILOSTAT verilerinde göçmenlerin geçirdiği ölümlü olmayan iş kazası sayıları da bulunmaktadır. ILOSTAT, göçmen sayılarını toplam ölümlü iş kazası sayısına dahil etmediğinden çalışmada da göçmen iş kazası sayıları kullanılmamıştır.

\section{Kaynak: SGK, 2019; ILOSTAT, 2019.}

Yıllar itibari ile farklılık incelendiğinde 2013 yılında ölümlü iş kazası verilerinde toplam sayı aynıdır. Sadece 1 kişi ile cinsiyette bir farklılık bulunmaktadır. 2014 yılı verileri incelendiğinde ILOSTAT verilerindeki fazla sayı nedeniyle yüzde fark1 -0,0013 olarak belirlenmiş̧ir. Bu fark da 2 kişiye denk gelmektedir. 2015 verilerinde de benzer bir durum bulunmakta ve farkın iki kişi ile $\sim-0,0016$ yüzdelik farka denk geldiği sonucuna ulaşılmıştır. Yine burada da ILOSTAT verileri SGK verilerine göre daha fazladır. Son olarak 2016 yılı verilerinde ise 4 kişilik bir farklılık bulunmaktadır. Yüzde fark1 0,0029 olarak hesaplanmıştır. Sonucun pozitif olması bize göstermektedir ki SGK verileri ILOSTAT verilerinde daha fazladır. Yani ulusal ölümlü iş kazası verileri ile uluslararası ölümlü iş kazası verileri neredeyse aynıdır. Ölümlü iş kazaları sayılarında SGK ve ILOSTAT verileri karşılaştırıldığında anlamlı bir 
farklılı̆̆ın olmadığı Grafik 5'te net olarak görülmektedir. Bu da göstermektedir ki uluslararası platformda beklenen verileri kaydetme yöntemini olması gerektiği gibi yürütebilmekteyiz.

Grafik 5. Ölümlü iş kazası verileri karşılaştırması.

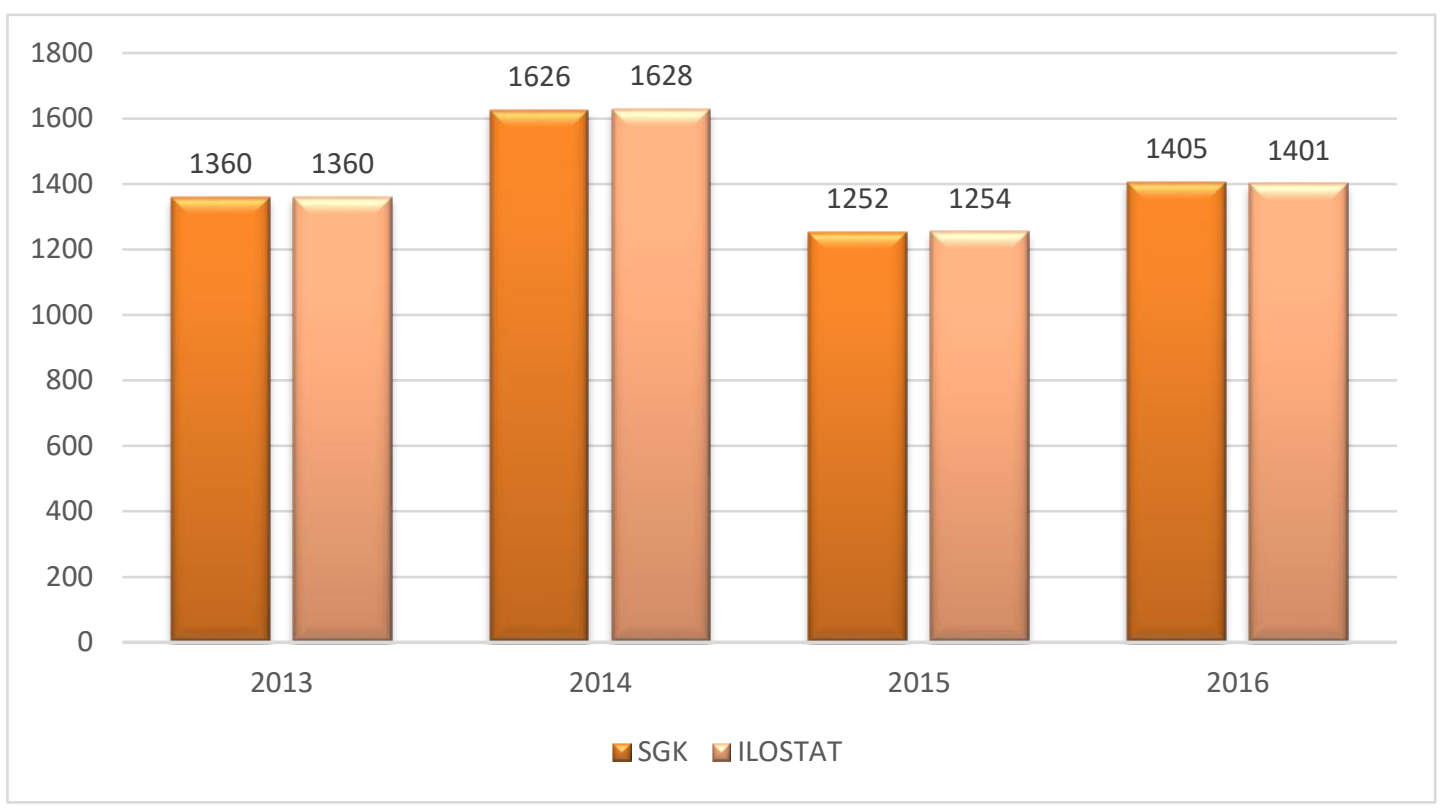

Kaynak: SGK, 2019; ILOSTAT, 2019.

Tablo 3, ölümlü iş kazalarının yaşandığı ekonomik faaliyet sınıflarını içermektedir. Ekonomik faaliyet sinıflarında ILOSTAT ve SGK tarafindan dikkate alınan NACE REV. 2 (EUROSTAT, 2008) kodları dikkate alınmıştır. Her ana kod altında bulunan diğer kodlar derlenerek toplam sayı çıkarılmıştır. Veriler incelendiğinde bu başlık altında da anlamlı bir farklılığın olmadığı görülmektedir. Birkaç kişi ile bazı farklar bulunmakta ancak bu farklılık Türkiye'deki durumu değiştirecek kadar güçlü değildir. Ölümlü iş kazalarında her yıl inşaat sektörünün ilk sırada olduğu da dikkat çekicidir. Farklılığın olmamasının bir sebebi de Türkiye'de tutulan iş kazası verilerinin uluslararası standartlara uygun olarak tutulmasından kaynaklanmaktadır.

Tablo 3. Ekonomik faaliyet sınıfina göre ölümlü iş kazası tablosu

\begin{tabular}{|c|c|c|c|c|c|c|c|c|}
\hline \multirow{2}{*}{ Sektörler } & \multicolumn{4}{|c|}{ SGK } & \multicolumn{4}{|c|}{ ILO } \\
\hline & 2013 & 2014 & 2015 & 2016 & 2013 & 2014 & 2015 & 2016 \\
\hline Tarım, Orman, Balıkçılık & 23 & 20 & 21 & 26 & 23 & 20 & 21 & 26 \\
\hline Maden. ve Taş Ocakçıllı̆̆ & 87 & 382 & 79 & 83 & 87 & 382 & 79 & 83 \\
\hline İmalat & 284 & 253 & 231 & 262 & 285 & 253 & 231 & 262 \\
\hline Elektrik, Gaz, Buhar ve & & & & & & & & \\
\hline $\begin{array}{l}\text { İklimlendirme Ürt. Ve } \\
\text { Dağ. }\end{array}$ & 10 & 15 & 30 & 15 & 10 & 15 & 30 & 15 \\
\hline $\begin{array}{l}\text { Su Temini; Kanalizasyon, } \\
\text { Atık Yönetimi }\end{array}$ & 12 & 15 & 22 & 23 & 12 & 15 & 22 & 23 \\
\hline İnşaat & 521 & 501 & 473 & 496 & 521 & 502 & 474 & 497 \\
\hline $\begin{array}{l}\text { Toptan ve Perakende } \\
\text { Ticaret }\end{array}$ & 82 & 79 & 71 & 91 & 83 & 79 & 71 & 91 \\
\hline Ulaştırma ve Depolama & 230 & 217 & 190 & 225 & 230 & 219 & 190 & 225 \\
\hline $\begin{array}{l}\text { Konaklama ve Yiyecek } \\
\text { Hizmeti Faaliyetleri }\end{array}$ & 17 & 28 & 33 & 34 & 17 & 28 & 33 & 34 \\
\hline Bilgi ve İletişim & 3 & 6 & 1 & 5 & 3 & 6 & 1 & 5 \\
\hline Mesleki, Bilimsel ve & 18 & 16 & 11 & 23 & 18 & 16 & 11 & 23 \\
\hline
\end{tabular}


Teknik Faaliyetler

İdari ve Destek Hiz. Faal.

Eğitim

İnsan Sağlığı ve Sosyal

Çalışmalar

Kültür, Sanat, Eğlence,

Dinlence ve Spor

Diğer Hizmet Faaliyetleri

Hane İçi Çalışmalar

Kaynak: ILOSTAT, 2019; EUROSTAT, 2008; SGK, 2019

\section{Sonuç ve Öneriler}

Sosyal Güvenlik Kurumu tarafindan yayımlanan veriler incelendiğinde, 2012 y1lında 6331 sayılı İş Sağlı̆̆ ve Güvenliği Kanunu'nun yürürlüğe girdiği tarihten itibaren toplam iş kazası sayısında sürekli artış olduğu görülmektedir. Hatta karşılaşılan diğer ilginç sonuç da iş kazası sayısındaki artışın nüfus artışından daha fazla yaşanmasıdır (Grafik 3). Bu artışın nedenleri arasında kanunun iş kazası bildirimini zorunlu tutması, iş güvenliği uzmanlarının iş yerlerinde zorunlu olarak çalışıyor olması, bildirimlerin eksik ya da yanlış yapılması ya da yapılmamasından dolayı ödenecek idari para cezaları, göçmen statüsündeki kişilerin çalışma hayatına dahil olmaları gibi pek çok nedenle ifade etmek mümkündür. Bu durumun ortaya çıkarılabilmesi için ilgili bakanlıkların desteği ve yönlendirmesi ile her işletmede ayrıntılı bir çalışma yürütülmelidir.

SGK tarafından yayımlanan verilerin doğruyu yansıtıp yansıtmadığı Uluslararası Çalışma Örgütü (ILO)'ne bağlı olarak çalışan ILOSTAT tarafindan yayımlanan verilerle karşılaştırıldığında ortaya çıkmaktadır. Veriler gösteriyor ki, Türkiye'de yaşanan iş kazaları ile ilgili veriler tutarlılığını korumaktadır. Ancak önemli farklılık 2016 yılı ölümlü olmayan iş kazası verisinde bulunmaktadır. $\mathrm{Bu}$ nedenle bildirim yapan kişilerin bu işin ciddiyetini anlamaları gerekmektedir. Türkiye'de yaşanan iş kazalarının SGK'ye bildiriminde ve sisteme girilmesinde tolerans gösterilemeyeceği gibi uluslararası düzeyde de hem Türkiye'nin itibarı hem de doğru verileri dünyaya ulaştırma adına özenli davranılmalıdır.

Doğrudan bu çalışma ile benzerlik göstermese de bu çalışmanın amacı olan veri karşılaştırmasını içeren başka çalışmalar da bulunmaktadır. Ceylan (2011, s. 18) tarafından yapılan çalışmada Türkiye'deki iş kazası verileri gelişmiş ülke verileri ile kıyaslanmıştır. Kıyaslamada SGK, ILO ve EUROSTAT verileri yollar itibari ile alınarak değerlendirilmiştir. Diğer bir çalışma Öçal ve Çiçek (2017, s. 616) tarafından yürütülmüştür. Çalışmada Türkiye ve Avrupa Birliğindeki iş kazası verilerini karşılaştırma yoluna gidilmiştir. Veriler, SGK, ILO ve EUROSTAT tarafindan resmi internet sayfalarında yayımlanan kaynaklar yoluyla elde edilmiştir. Bir diğer çalışma ise Kahraman ve Özdemir (2019, s. 110) tarafından yürütülen ve Kömür madenciliğindeki kazaların karşılaştırıldığı Türkiye-Çin örneğini içermektedir. Veriler, SGK ve Çin İşçi Bülteni tarafından yayımlanan kaynaktan alınmıştır.

Özellikle iş yerlerinde yaşanan kazalar, iş yerlerinin hedeflerinin tutmaması, devlet desteğinden yoksun kalma gibi nedenlerle kayıt altına alınamayabilir. Bunun önüne geçilebilmesi için iş yerlerinde istihdam edilen çalışanların da kendi bildirimlerini yapabilecekleri bir sistem geliştirilmelidir. Ancak sistemin çalışanlar tarafından kötüye kullanılmaması için gerekli idari yaptırımların da uygulanması daha doğru olacaktır. Ayrıca kazaların artarak devam etmesi önlemlerin eksikliklerini de göstermektedir. Bu nedenle ulusal düzeyde uygulanan önlemlerin önlem uygulayan kişiler yüzünden mi yoksa iş yerlerindeki zafiyetten kaynaklı bir başarısızlık nedeniyle mi yetersiz kaldığı konusu da idari makamlarca araştırılmalıdır. 


\section{Kaynakça}

Akar, Ş.S. ve Ş1k, A. (2015). Konaklama ve beslenme işletmelerinde iş să̆llğl ve güvenliği. Ankara: Detay Yayıncılık.

Akpınar, T. (2018). İş sağlı̆̆ ve güvenliği hukuku. Bursa: Ekin Yayınevi.

Benach J., Muntane C. ve Santana (Chairs) V. (2007). Employment conditions and health inequalities, final report to the who, commission on social determinants of health (CSDH), Employment Conditions Knowledge Network (EMCONET). https://www.who.int/social_determinants/resources/articles/emconet_who_report.pdf (Erişim tarihi: 16.09.2019).

Can, İ. (2013). Sistematik aile sosyolojisi. Konya: Çizgi Kitabevi.

Ceylan, H. (2011). Türkiye'deki iş kazalarının genel görünümü ve gelişmiş ülkelerle k1yaslanmas1. International Journal of Engineering Research and Development, (3), (2)

Doğan, A. (2013). Türkiye'de toplumsal cinsiyet eşitliğini sağlamaya yönelik hizmet veren kamu kurumları ve hizmetleri üzerine bir değerlendirme. KSÜ Sosyal Bilimler Dergisi, 10 (2), 75-95.

European Commission (2017). Communication From The Commission To The European Parliament, The Council, The European Economic and Social Committee and The Committee of The Regions. https://ec.europa.eu/social/BlobServlet?docId=16874\&langBenachId=en (Erişim tarihi: 11.09.2019).

EUROSTAT (2008), Statistical classification of economic activities in the European Community. https://ec.europa.eu/eurostat/documents/3859598/5902521/KS-RA-07-015EN.PDF. (Erişim tarihi: 09.03.2021).

Fontaneda, I., López, M. A. C., Alcántara, O. J. G., \& Ritzel, D. O. (2019). Gender differences in lost work days due to occupational accidents. Safety science, 114, 23-29. doi.: https://doi.org/10.1016/j.ssci.2018.12.027

Hansen, C. D. (2019). Comparing fatal occupational accidents in Denmark and Sweden 19932012. Occupational medicine, 69(4), 283-286. doi.: https://doi.org/10.1093/occmed/kqz064

International Labor Organization (2016). 2016-2020 Occupational Safety and Health Policy Document.

http://www.ilo.org/dyn/legosh/en/f?p=LEGPOL:503:8753526197935:::503:P503_REFERE

NCE_ID:311978 (Erişim tarihi: 11.09.2019).

ILOSTAT (2019). Data collection and production. https://ilostat.ilo.org/about/data-collectionand-production/ (Erişim tarihi: 12.09.2019).

Jabbari, M., \& Ghorbani, R. (2016). Developing techniques for cause-responsibility analysis of occupational accidents. Accident Analysis \& Prevention, 96, 101-107. doi.: https://doi.org/10.1016/j.aap.2016.07.039

Jeong, B. Y., \& Shin, D. S. (2016). Characteristics of occupational accidents in Korean, Chinese, Japanese and Western cuisine restaurants. Human Factors and Ergonomics in Manufacturing \& Service Industries, 26(3), 316-322. doi.: https://doi.org/10.1002/hfm.20647

Kahraman, L., ve Özdemir, A.C. (2017). Kömür madenciliğinde ölümlü iş kazalarının karşılaştırılması: Türkiye-Çin örneği. Uluslararası Maden İşletmelerinde İşçi Sağlığ1 ve İş Güvenliği Sempozyumu', Adana. 
Lay, A. M., Saunders, R., Lifshen, M., Breslin, F. C., LaMontagne, A. D., Tompa, E., \& Smith, P. M. (2017). The relationship between occupational health and safety vulnerability and workplace injury. Safety science, 94, 85-93.

Moyce, S. C., \& Schenker, M. (2018). Migrant workers and their occupational health and safety. Annual review of public health, 39, 351-365. doi.: https://doi.org/ 10.1146/annurevpublhealth-040617-013714

Öçal, M., ve Çiçek, Ö. (2017). Türkiye ve Avrupa Birliği’nde iş kazası verilerinin karşılaştırmalı analizi, HAK-IŞ Uluslararası Emek ve Toplum Dergisi, 6(16), 616-637.

Pietilä, J., Räsänen, T., Reiman, A., Ratilainen, H., \& Helander, E. (2018). Characteristics and determinants of recurrent occupational accidents. Safety science, 108, 269-277. doi.: https://doi.org/10.1016/j.ssci.2017.12.020

KAYSIS (2020a). 5510 sayll Sosyal Sigortalar ve Genel Salık Sigortasi Kanunu. https://kms.kaysis.gov.tr/Home/Goster/28721 (Erişim tarihi: 09.03.2021).

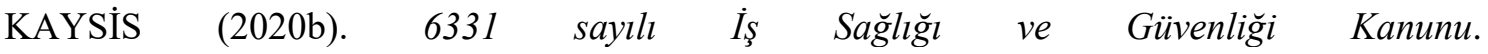
https://kms.kaysis.gov.tr/Home/Goster/32403 (Erişim tarihi: 09.03.2021).

KAYSIS (2020c). Türkiye Cumhuriyeti Anayasasl. https://kms.kaysis.gov.tr/Home/Goster/31533 (Erişim tarihi: 09.03.2021).

T.C. 1982 Anayasas1. https://www.tbmm.gov.tr/anayasa/anayasa_2018.pdf (Erişim tarihi: 18.09.2019).

Sosyal Güvenlik Kurumu (2019). SGK Istatistik Ylllkklarl, http://www.sgk.gov.tr/wps/portal/sgk/tr/kurumsal/istatistik/sgk_istatistik_yilliklari (Erişim tarihi: 12.09.2019).

Sümer, H. H. (2017). İşs sağllğı ve güvenliği hukuku. Ankara: Seçkin Yayınevi.

Telman, N., Önen, L. ve Özgeldi, M. (2015). Psikolojide iş să̆lı̆̆l- iş güvenliği. I. Bask1, Ankara.

Yıldırım, Ç. V. \& Asal, Ö. (2012). Küçük ve orta büyüklükteki işletmelerde (kobi) iş sağlığı ve güvenliğini etkileyen faktörlerin araştırılması: Ankara imalat sanayi örneği. Türkiye Sosyal Araştırmalar Dergisi, 161(161), 103-122.

Yiğit, A. (2011). İş güvenliği. Bursa: Alfa Aktüel Yayınları.

\section{ETIKK ve BİLIMSEL İLKELER SORUMLULUK BEYANI}

$\mathrm{Bu}$ çalışmanın tüm hazırlanma süreçlerinde etik kurallara ve bilimsel atıf gösterme ilkelerine riayet edildiğini yazarlar beyan eder. Aksi bir durumun tespiti halinde Afyon Kocatepe Üniversitesi Sosyal Bilimler Dergisi'nin hiçbir sorumluluğu olmayıp, tüm sorumluluk makale yazarlarına aittir.

\section{ARAŞTIRMACILARIN MAKALEYE KATKI ORANI BEYANI}

1. yazar katk1 oranı: $\% 70$

2. yazar katkı oranı: $\% 30$ 